\title{
Diverticulite em Adolescente com Síndrome de Williams: Relato de Caso
}

\author{
Diverticulitis in Adolescent with Williams Syndrome: Case Report
}

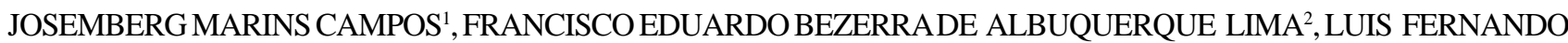

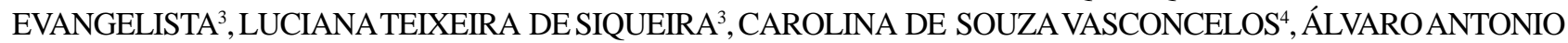 \\ BANDEIRA FERRAZ ${ }^{2}$,EDMUNDO MACHADOFERRAZ ${ }^{5}$
}

${ }^{1}$ Professor do Depto. de Cirurgia-UFPE; ${ }^{2}$ Professor Adjunto do Depto. de Cirurgia-UFPE, TSBCP; ${ }^{3}$ Cirurgiã(o) do Serviço de Cirurgia Geral do HC-UFPE; ${ }^{4}$ Bolsista do CNPq, UFPE; ${ }^{5}$ Professor Titular do Depto. de Cirurgia-UFPE e

Chefe do Serviço de Cirurgia Geral - HC-UFPE.

\begin{abstract}
CAMPOS JM; LIMA FEBA; EVANGELISTA LF; SIQUEIRA LT; VASCONCELOS CS; FERRAZ AAB; FERRAZ EM. Diverticulite em adolescente com Síndrome de Williams: Relato de caso. Rev bras Coloproct, 2009;29(1): 088-091.

RESUMO: A Síndrome de Williams é uma doença genética rara, atribuída a deleção do gene da elastina no cromossomo 7. É caracterizada por estenose de aorta, divertículos de bexiga, constipação, retardo mental leve, fácies dismórfica, fraqueza da parede da bexiga e do cólon que levam ao surgimento de divertículos. Relata-se um caso de diverticulite aguda em paciente de 18 anos, o resultado do tratamento clínico durante 5 anos e o diagnóstico diferencial de abdome agudo nesta doença. A indicação de colectomia eletiva é discutida, considerando o pouco conhecimento da história natural da diverticulite nesta síndrome.
\end{abstract}

Descritores: Diverticulite, abdome agudo, adolescente, Síndrome de Williams.

\section{INTRODUÇÃO}

É uma síndrome congênita, de causa desconhecida e caracterizada por alterações craniofaciais, cardiovasculares, cognitivas, musculoesqueléticas, urológicas e gastroenterológicas, além de hipercalcemia infantil e constipação crônica ${ }^{1}$. As complicações urológicas são frequentes, principalmente relacionadas a divertículos de bexiga, mas sintomas decorrentes de divertículos de cólon são menos comuns, havendo poucos relatos na literatura de diverticulite em adolescentes com tal síndrome ${ }^{2}$.

A síndrome de Williams (SW) ocorre predominantemente de forma esporádica em um a cada 20.000 recém-nascidos vivos, havendo baixo risco de recorrência, sendo extremamente rara a determinação familiar ${ }^{2}$. Por ser rara, essa doença pode causar erro ou confusão diagnóstica, importando ao médico conhecê-la para permitir o adequado acompanhamento.

Os autores apresentam um caso de diverticulite aguda em um paciente de 18 anos com SW, que vem sendo tratado clinicamente há cinco anos. Objetiva-se ainda discutir o difícil diagnóstico diferencial de abdome agudo nesta doença, quando ocorre na adolescência, além das possibilidades terapêuticas para a diverticulite associada, considerando o pouco conhecimento da sua história natural.

\section{RELATO DE CASO}

Em dezembro de 2003, um adolescente de 18 anos de idade, apresentou um quadro de dor no hipogástrio e polaciúria por 12 horas, sendo diagnosticada 
infecção urinária a partir da interpretação do sumário de urina. Isto foi corroborado com o relato dos familiares de que o paciente era portador da SW, e que poderia desenvolver divertículos na bexiga, predispondo a sintomas urinários baixos. Neste primeiro episódio, o tratamento foi realizado com sucesso em ambiente domiciliar, usando ciprofloxacin.

O paciente já possuía o diagnóstico da SW desde um ano de idade através do teste "fluorescence in situ hybridization" (FISH), quando foi realizada cirurgia cardíaca para correção de comunicação interventricular. Na ocasião, houve orientação médica para as possíveis ocorrências relacionadas.

Em junho de 2004, seis meses após, ocorreu recidiva do quadro clínico já descrito, sendo acrescido de hemograma com leucocitose e desvio à esquerda. O sumário de urina foi normal e não houve melhora da dor abdominal três dias após o início de ciprofloxacin oral. A radiografia simples do abdome não apresentava alterações significativas, mas a ultrassonografia mostrava imagem tubular no hipogástrio, próximo à bexiga, sugestiva de apendicite aguda.

A tomografia axial computadorizada, com contraste iodado por via oral, mostrou pequenas imagens saculiformes na espessa parede do sigmoide (Figura 1). Não foi identificado abscesso e nem fístula para a

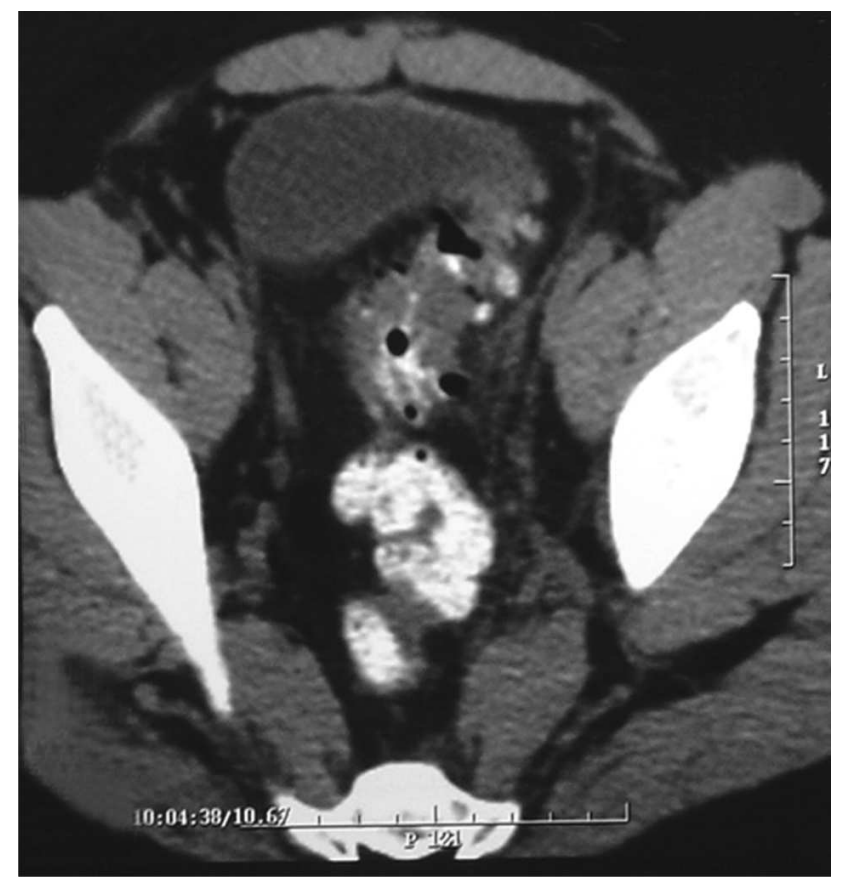

Figura 1 - Tomografia de abdome com contraste mostrando pequenas imagens saculiformes, espessamento do sigmóide e bexiga sem divertículos. bexiga, cujo quadro tomográfico foi classificado como diverticulite aguda Hinchey 1. Assim, o paciente foi internado com a seguinte conduta: hidratação, suspensão da dieta por via oral, analgésico e antibiótico parenteral, sendo substituído ciprofloxacin por ceftriaxona e metronidazol.

Nos quatro primeiros dias de internamento hospitalar, houve boa evolução do quadro clínico, com melhora da dor e da distensão abdominal. Foi iniciada dieta líquida por via oral, havendo aceitação satisfatória e progressiva. Os exames laboratoriais, inclusive o leucograma, tornaram-se normais.

Após dois meses, os divertículos foram confirmados através de enema opaco (Figura 2). No momento, o paciente está assintomático e vem recebendo acompanhamento especializado de geneticista, cardiologista, urologista e proctologista, fazendo uso de dieta laxante e com suplemento de fibras.

No seguimento de cinco anos, o paciente apresentou três episódios de dor em fossa ilíaca esquerda,

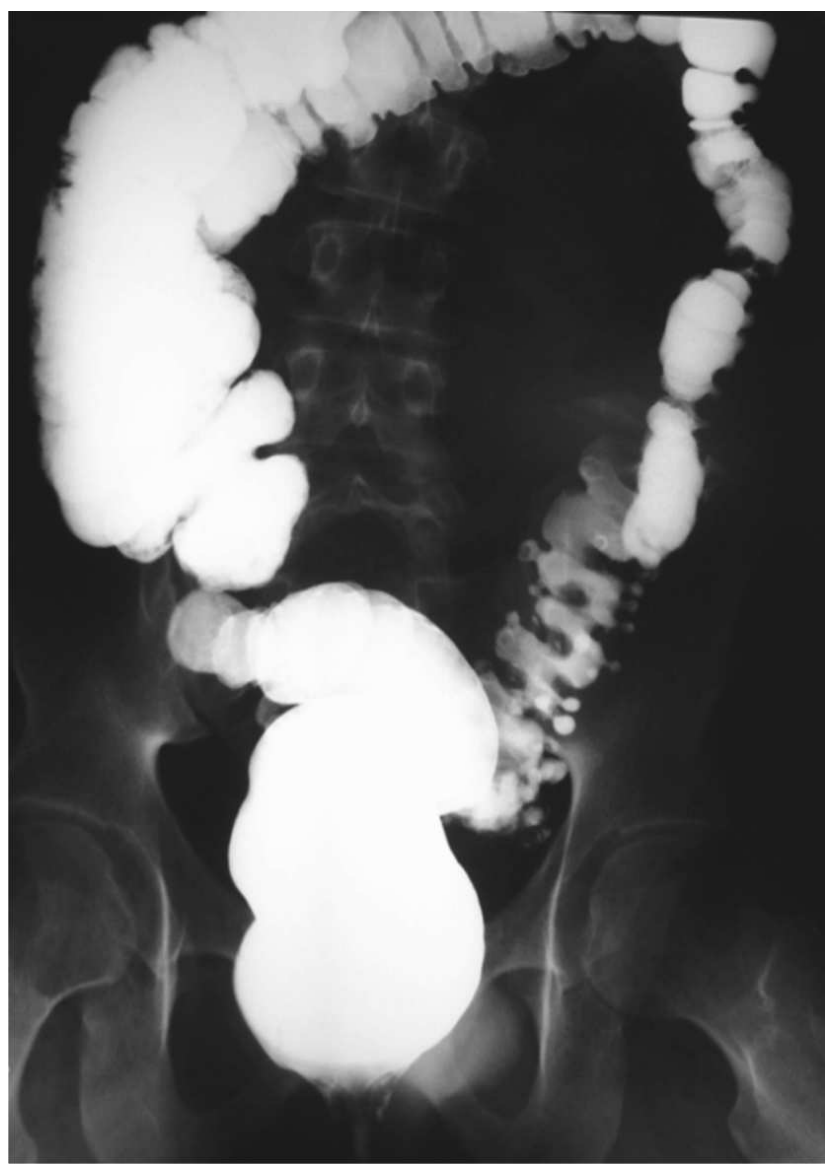

Figura 2 - Enema opaco mostrando cólon espástico e divertículos de óstio estreito restritos ao sigmóide. 
sendo presumido o diagnóstico de diverticulite aguda não complicada e realizado tratamento com antibiótico oral, além de orientação higienodietética em ambiente domiciliar.

\section{DISCUSSÃO}

Esta síndrome foi descrita inicialmente por Williams et al, em 1961 ${ }^{1,2}$. Consiste em defeito molecular caracterizado pela diminuição de elastina, secundária a exclusão da cópia do gene desta proteína em $90 \%$ dos pacientes, que é mapeado na banda 7q11.23 do cromossomo $7^{2-4}$. O diagnóstico é feito de maneira rápida e eficaz através do teste FISH, usando sonda específica para o gene da elastina; todavia, em 5 a $10 \%$ dos casos, pode não ocorrer deleção da elastina ${ }^{4}$. O paciente desse relato teve o diagnóstico confirmado com um ano de idade através do teste de FISH.

A história natural das alterações gastroenterológicas, no primeiro ano de vida, indica dificuldade de alimentação devido aos vômitos, cólicas intestinais, constipação, irritabilidade e choro excessivo, resultando em retardo de crescimento. Estas alterações decorrem da hipercalcemia secundária ao distúrbio do metabolismo do cálcio, que tende a melhorar na adolescência ${ }^{2}$. No entanto, a constipação pode persistir e na ausência de elastina, pode levar ao surgimento de divertículos de cólon e diverticulite ${ }^{4,5}$. Em nosso caso, conforme relato dos familiares, a evolução clínica foi semelhante ao descrito acima, resultando em diverticulite numa fase precoce da vida.

Adolescente que recebe atendimento médico de urgência por dor abdominal localizada e sinais de irritação peritoneal em hipogástrio apresenta quadro clínico bastante sugestivo de apendicite aguda, uma vez que esta é a principal causa de abdome agudo cirúrgico nesta faixa etária ${ }^{6}$. Todavia, em portadores da Síndrome de Williams, deve-se insistir no diagnóstico diferencial, através de investigação complementar ${ }^{5,7}$. Nesses pacientes, a possibilidade de afecção urológica ou relacionada a presença de divertículos colônicos é real e deve ser afastada.

Assim, nessa síndrome não é adequado indicar apendicectomia baseado apenas no quadro clínico e no diagnóstico ultrassonográfico, o que é aceitável para a maioria dos adolescentes sem esta síndrome, quando é frequente a ocorrência de apendicite aguda ${ }^{6}$.

A tomografia de abdome com contraste tornase um exame essencial na avaliação de pacientes com
SW e que apresentem dor aguda em hipogástrio e/ou fossa ilíaca esquerda. No paciente atual, houve dificuldade em se estabelecer o diagnóstico definitivo de diverticulite, o qual foi confirmado somente diante do achado tomográfico.

Doença diverticular é incomum em jovens abaixo de 40 anos, que constitui entre 5 e $7 \%$ dos adultos abaixo de 40 anos, sendo rara em adolescente. Quando presente em pacientes abaixo de 18 anos, pode-se associar a desordens do tecido conectivo como a síndrome de Marfan ou uso de esteroides ${ }^{6}$.

Em 2005, Deshpande et al ${ }^{7}$, relatam um caso de um adolescente de 17 anos com Síndrome de Williams e dor abdominal interpretada como infecção urinária e gastrenterite, que também foi submetido a apendicectomia. A tomografia de abdome possibilitou o diagnóstico diferencial entre diverticulite e colite isquêmica. Não houve resposta a antibióticos e o paciente realizou uma simoidectomia a Hartmann, ocorrendo óbito devido a hemorragia pulmonar ${ }^{7}$. Este caso difere do presente relato já que vem ocorrendo boa resposta ao uso de antibióticos e não houve diverticulite complicada.

A indicação de colectomia de urgência se impõe nos casos em que há diverticulite com complicação grave, como peritonite purulenta difusa e peritonite fecal (Hinchey 3 e 4$)^{8,9}$. Há também uma tendência a se indicar colectomia eletiva nos casos complicados com abscesso localizado e que foram tratados clinicamente na fase aguda ${ }^{8,9}$. Porém, quando há diverticulite aguda não complicada e com boa resposta ao tratamento medicamentoso, mesmo após recidivas, é possível realizar tratamento clínico ${ }^{8-12}$.

Como o nosso paciente obteve boa resposta ao tratamento não cirúrgico e evoluiu sem complicações, optou-se por acompanhamento mais rigoroso, com avaliações clínicas periódicas em menor intervalo de tempo. Os três episódios de dor abdominal que ocorreram em 5 anos melhoraram após curto período de uso de antibióticos, dispensando atendimento hospitalar.

Partsch et al ${ }^{13}$, em 2005, apresentaram 10 pacientes com diverticulite e SW, com idade entre 17 e 39 anos. Houve alta taxa de complicação e oito pacientes evoluíram com doença complicada, sendo submetidos a múltiplas cirurgias. A terapia conservadora foi bem sucedida apenas em dois pacientes com diverticulite.

Contudo, ainda há escassa literatura a respeito do tema, ${ }^{7,13}$ e pouco conhecimento sobre a história natural da diverticulite nessa síndrome. Assim, a terapêutica conservadora pode ser uma conduta prudente. 
ABSTRACT: The Syndrome of Williams is a rare genetic illness, attributed the deletion of the gene of the elastin in chromosome 7. It is characterized by aortic stenosis, bladder diverticula's, constipation, light mental retardation, dysmorphic facies, weakness of the wall of the bladder and colon that they lead to the sprouting of diverticula. A case of acute diverticulitis in patient of 18 years is told, the result of the clinical treatment during 5 years and the differential diagnosis of acute abdomen in this illness. The indication of elective colectomy is argued, considering the unfamiliarity of the natural history of the diverticulitis in the syndrome.

Key words: Diverticulitis, acute abdomen, adolescent, Williams Syndrome.

\section{REFERÊNCIAS}

1. Williams JC, Barratt-Boyes BG, Lowe JB. Supravalvular aortic stenosis. Circulation. 1961 Dec;24:1311-8.

2. Morris CA, Demsey SA, Leonard CO, Dilts C, Blackburn BL. Natural history of Williams syndrome: physical characteristics. J Pediatr. 1988 Aug;113(2):318-26

3. Ewart AK, Morris CA, Ensing GJ, Loker J, Moore C, Leppert M, Keating M. A human vascular disorder, supravalvular aortic stenosis, maps to chromosome 7. Proc Natl Acad Sci U S A. 1993 Apr;90(8):3226-30.

4. Nickerson E, Greenberg F, Keating MT, McCaskill C, Shaffer LG. Deletions of the elastin gene at $7 \mathrm{q} 11.23$ occur in approximately $90 \%$ of patients with Williams syndrome. Am J Hum Genet. 1995 May;56(5):1156-61.

5. Cagle AP, Waguespack SG, Buckingham BA, Shankar RR, Dimeglio LA. Severe infantile hypercalcemia associated with Williams syndrome successfully treated with intravenously administered pamidronate. Am J Med Genet A. 2005 Aug;137(1):52-4.

6. Afzal NA, Thomson M. Best Pract Res Clin Gastroenterol. 2002 Aug;16(4):621-34.

7. Deshpande AV, Oliver M, Yin M, Goh TH, Hutson JM. Severe colonic diverticulitis in an adolescent with Williams syndrome. J Paediatr Child Health. 2005 Dec;41(12):687-8.
8. Nelson RS, Velasco A, Mukesh BN. Management of diverticulitis in younger patients. Dis Colon Rectum. 2006 Sep;49(9):1341-5.

9. Jacobs DO. Clinical practice. Diverticulitis. N Engl J Med. 2007 Nov;357(20):2057-66.

10. Guzzo J, Hyman N. Diverticulitis in young patients: is resection after a single attack always warranted? Dis Colon Rectum. 2004 Jul;47(7):1187-90.

11. Farmakis N, Tudor RG, Keighley MR. The 5-year natural history of complicated diverticular disease. Br J Surg. 1994 May;81(5):733-5.

12. Biondo S, Parés D, Martí Ragué J, Kreisler E, Fraccalvieri D, Jaurrieta E. Acute colonic diverticulitis in patients under 50 years of age. Br J Surg. 2002 Sep;89(9):1137-41

13. Partsch CJ, Siebert R, Caliebe A, Gosch A, Wessel A, Pankau R. Sigmoid diverticulitis in patients with Williams-Beuren syndrome: relatively high prevalence and high complication rate in young adults with the syndrome. Am J Med Genet A. 2005 Aug;137(1):52-4.

\section{Endereço para Correspondência:} JOSEMBERG MARINS CAMPOS

Rua Vigário Barreto, 127, apt. 802

Graças, Recife - Brasil

CEP: $52020-140$

Fones (55 81) 3241-3763 / 9973-8741 / 3441-4460

E-mail:berg@elogica.com.br 